\title{
Primary Hyperparathyroidism with Negative Pre-operative Imaging: A review of current and emerging localisation modalities
}

\author{
Zhi Guang Ng, Cherng Jye Seow
}

Tan Tock Seng

Department of Endocrinology, Tan Tock Seng Hospital, Singapore

\section{BACKGROUND}

Primary hyperparathyroidism is commonly caused by a single hyperfunctioning adenoma ( $80-85 \%$ of cases). Localisation of the adenoma preoperatively via various imaging modalities allows for a focused and minimally invasive approach to parathyroid surgery, negating the need for invasive bilateral neck exploration, thus reducing surgical morbidity. We present a patient with primary hyperparathyroidism that was biochemically confirmed. However, the adenoma was not localised pre-operatively. She underwent surgical exploration and the adenoma was eventually found to be embedded in the right thyroid tissue. We discuss various localisation modalities available to help localise the lesion pre-operatively.

\section{CASE DESCRIPTION}

A 65-year-old Chinese lady was admitted under the Department of Orthopaedics for a left neck of femur fracture. A left bipolar hemiarthroplasty was performed. She was subsequently found to have hypercalcemia and primary hyperparathyroidism. History was unremarkable for renal impairment, drug related causes or malignancy. There was no known family history of hypercalcemia. She was otherwise asymptomatic. Physical examination was unremarkable. Her calcium-creatinine ratio clearance ratio of $2.12 \%$ was suggestive of Primary Hyperparathyroidism. Her 25-OH Vitamin D level was also noted to be low at 18ug/L. Ultrasonography (Fig 1) did not localise any hypoechoeic ovoid structures but showed multiple thyroid nodules. Fine needle aspiration cytology (FNAC) of the thyroid nodules was negative for malignancy. Dual tracer parathyroid scintigraphy did not reveal any sestamibi-avid or enlarged parathyroid lesion. A total thyroidectomy and exploratory parathyroidectomy subsequently revealed a right parathyroid adenoma embedded within the thyroid

\section{INVESTIGATIONS}

\begin{tabular}{|l|c|c|}
\hline Test & Result & Reference Range \\
\hline Calcium (adj) & $\underline{\mathbf{2 . 8 2}}$ & $2.15-2.58 \mathrm{mmol} / \mathrm{L}$ \\
\hline Phosphate & 0.9 & $0.8-1.6 \mathrm{mmol} / \mathrm{L}$ \\
\hline PTH & $\underline{\mathbf{1 6 . 2}}$ & $0.8-6.8 \mathrm{pmol} / \mathrm{L}$ \\
\hline 25-OH Vit D & $\underline{\mathbf{1 8}}$ & $20-50 \mathrm{ug} / \mathrm{L}$ \\
\hline $\begin{array}{l}\text { Ca/Cr clearance } \\
\text { ratio }\end{array}$ & $2.12 \%$ & $\begin{array}{c}<1 \%: \mathrm{FHH} \\
>2 \%: \mathrm{PHPT}\end{array}$ \\
\hline ALP & 50 & $38-126 \mathrm{u} / \mathrm{L}$ \\
\hline Thyroid Panel & \multicolumn{2}{|c|}{ Normal } \\
\hline Myeloma Panel & Negative for Paraproteins \\
\hline
\end{tabular}

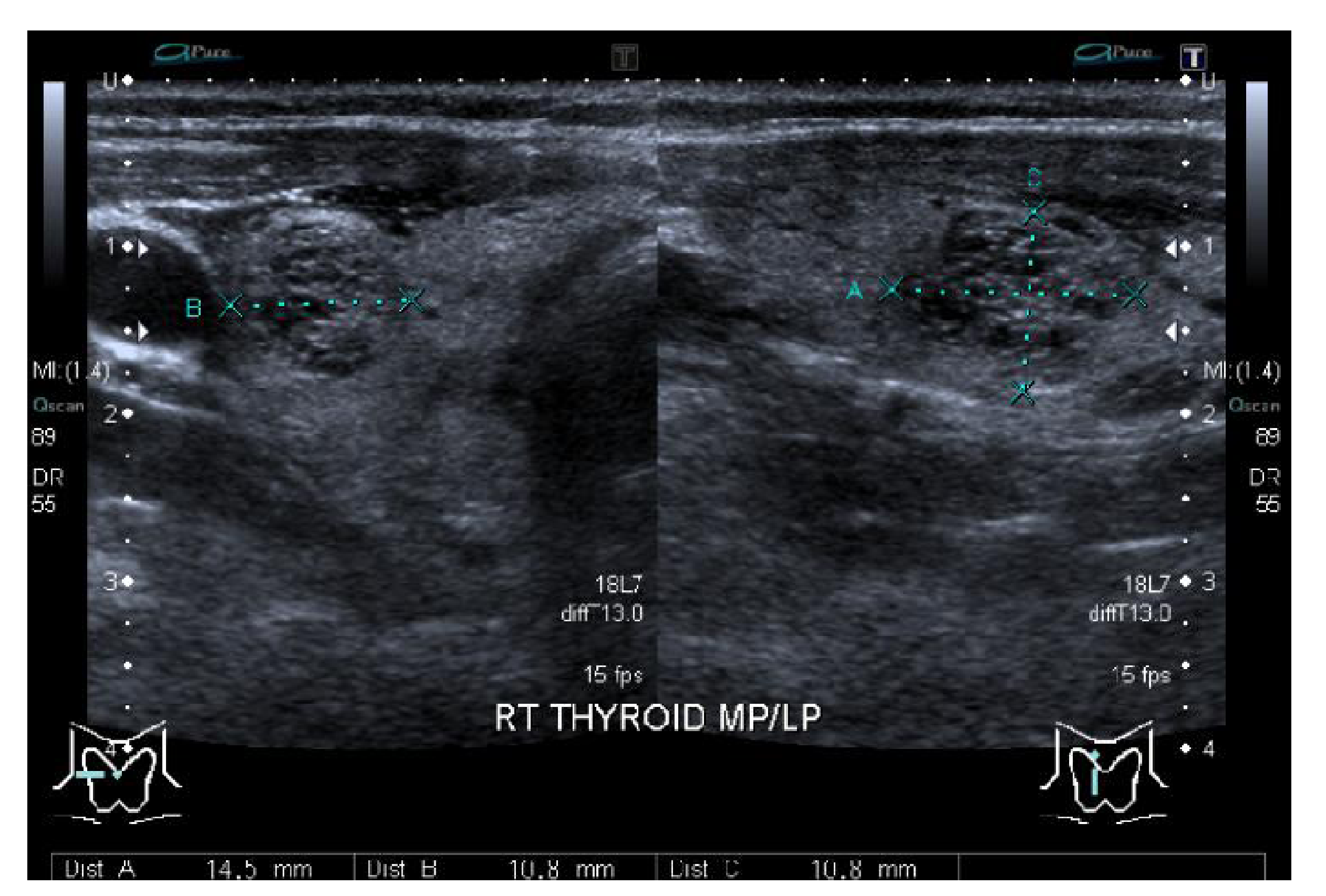

Figure 1: Ultrasound of the thyroid $\mathrm{mid} /$ lower pole

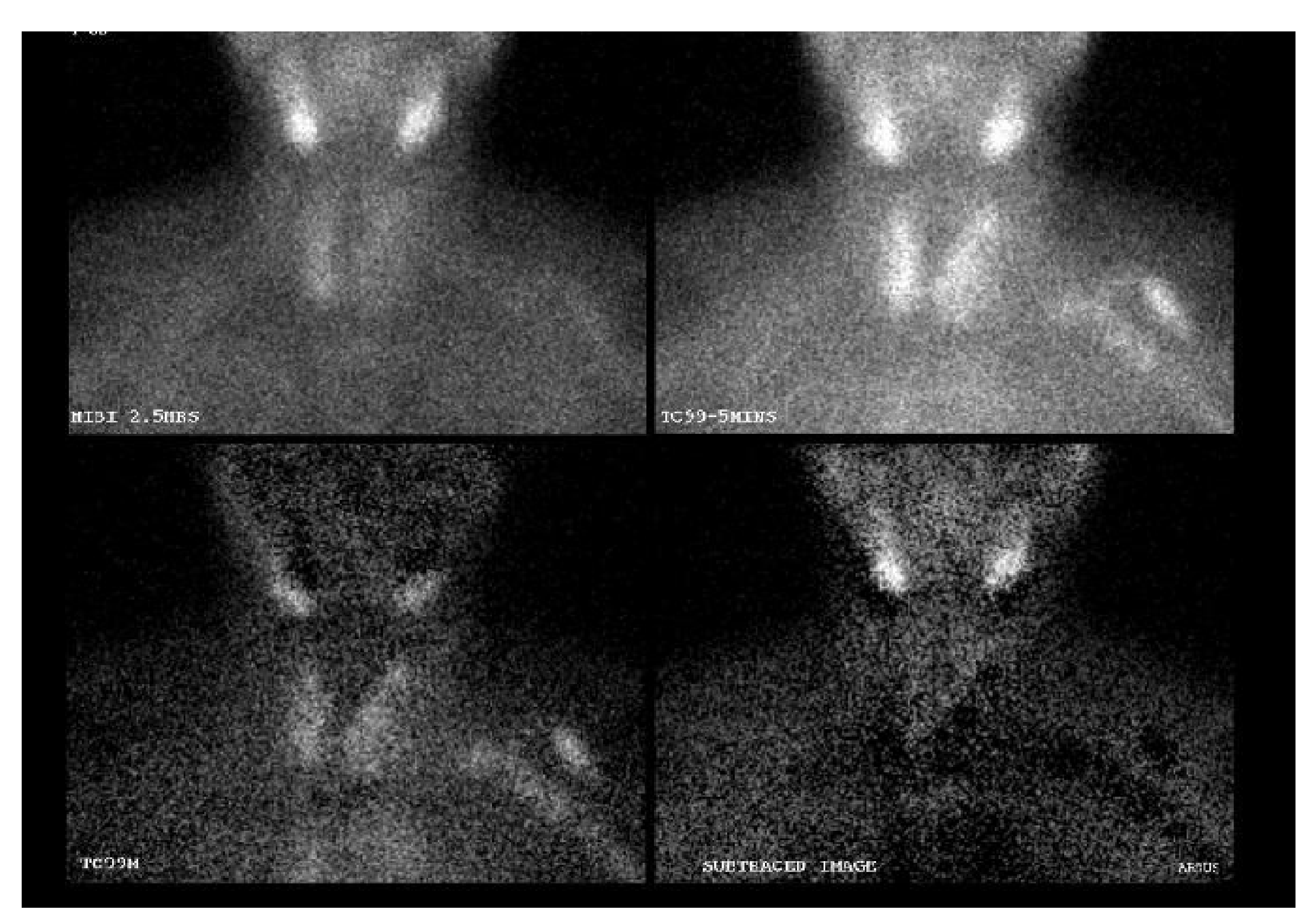

Figure 2: Dual tracer parathyroid scintigraphy (Tc-99m sestamibi and Tc-99m pertechnetate)

\section{DISCUSSION}

Non-invasive modalities in pre-operative localisation of parathyroid adenomas include ultrasonography, parathyroid scintigraphy, sestamibi-single photon emission computed tomography (SPECT), subtraction thyroid scan, 4-dimensional CT (4DCT), Positron emission tomography (PET) and Magnetic Resonance Imaging (MRI). Combination techniques have been used, and in particular, scintigraphy combined with SPECT possesses the highest positive predictive value and is the current gold standard modality for preoperative localisation. However, SPECT is not readily available at some centres and therefore scintigraphy is often used as the initial study. The sensitivity of scintigraphy is decreased in 4-gland hyperplasia, double adenomas or concomitant thyroid disease. Other combination techniques include SPECT/CT and 11-Cmethionine PET/CT.

Recent case reports have shown F18-fluorocholine PET/CT to be useful in localisation in scintigraphy-SPECT/CT-negative parathyroid adenomas. However, the cost for this novel modality remains considerably high and requires further validation from larger studies/trials.

Invasive modalities such as selective venous sampling (SVS) are generally reserved for patients with recurrent or persistent hyperparathyroidism. However, studies have shown it to be equivocal in its role before revision surgery compared to noninvasive modalities

\begin{tabular}{|l|c|c|}
\hline Imaging modality & Sensitivity (\%) & Positive predictive value (\%) \\
\hline Sestamibi & $71-79$ & $72-95$ \\
\hline Sestamibi-SPECT & $70-81$ & $91-95$ \\
\hline Ultrasound & $64-91$ & $83-96$ \\
\hline 4D-CT & $83-95$ & $88-99$ \\
\hline MRI & $40-85$ & N.A \\
\hline MET-PET-CT & $79-90$ & $93-94$ \\
\hline
\end{tabular}

\section{CONCLUSION}

The pre-operative localisation of a solitary adenoma in PHPT remains a challenge despite new, emerging techniques.

\section{REFERENCES}

Cheung K, Wang TS, Farrokhyar F, et al. A meta-analysis of preoperative localization techniques for patients with primary hyperparathyroidism. Ann Surg Oncol 2012; 19:577.

Mihai R, Simon D, Hellman P. Imaging for primary hyperparathyroidism--an evidence-based analysis. Langenbecks Arch Surg 2009; 394:765.

Weber T, Maier-Funk C, Ohlhauser D, et al. Accurate Preoperative Localization of Parathyroid Adenomas With C-11 Methionine PET/CT. Ann Surg 2013; 257:1124.

Daniel H. van Raalte et al. F18-Choline PET/CT: a novel tool to localize parathyroid adenoma? Clinical Endocrinology 2015; 10.1111/cen.12681

Witteveen JE et al. The role of selective venous sampling in the management of persistent hyperparathyroidism revisited. Eur J Endocrinol. 2010. 163(6):945-52

Schalin-Jäntti C et al. Planar scintigraphy with $1231 / 99 \mathrm{mTC}$-sestamibi, $99 \mathrm{mTC}$-sestamibi SPECT/CT, 11C-methionine PET/CT, or selective venous sampling before reoperation of primary hyperparathyroidism? J Nucl Med. 2013. 54(5):739-47. 